\title{
Educação física escolar na educação infantil: uma revisão sistemática
}

\section{School physical education in early childhood education: an systematic review}

\section{Educación física escolar en educación infantil: una revisión sistemática}

\author{
iD (9) Uirá de Siqueira Farias \\ Universidade São Judas, São Paulo, SP, Brasil \\ e-mail: uirasiqueira@yahoo.com.br \\ iD (9) Daniel Teixeira Maldonado \\ Instituto Federal de São Paulo, São Paulo, SP, Brasil \\ e-mail: danieltmaldonado@yahoo.com.br \\ iD?Vinicius dos Santos Moreira \\ Universidade São Judas, São Paulo, SP, Brasil \\ e-mail: vinicius_s_moreira@hotmail.com \\ iD) Elisabete dos Santos Freire \\ Universidade São Judas, São Paulo, SP, Brasil \\ e-mail: elisabetefreire@uol.com.br \\ iD Graciele Massoli Rodrigues \\ Universidade São Judas, São Paulo, SP, Brasil \\ e-mail: prof.graciel@usjt.br
}

\begin{abstract}
Resumo: Esta pesquisa teve como objetivo analisar as publicações científicas sobre a Educação Física Escolar (EFE) na Educação Infantil (El). Foi realizada uma revisão sistemática em todas as revistas da Educação e da Educação Física listadas no Web-Qualis (2013-2016), classificadas de A1 até B5 disponíveis online, entre 2010 a 2019. Foram encontrados 81 estudos que versavam sobre essa temática. Currículos, propostas pedagógicas e experiências de ensino estão sendo produzidos pelos docen-
\end{abstract}


tes de Educação Física que atuam nesse ciclo de escolarização a partir de múltiplas manifestações da cultura corporal, além do trabalho coletivo e o respeito aos saberes das crianças, apesar dos desafios que se originam na formação inicial e se perpetuam na formação continuada.

Palavras-chave. Análise sistemática. Educação. Educação Infantil. Educação Física.

Abstract: This research aimed to analyze scientific publications on School Physical Education in Early Childhood Education. An systematic review was carried out in all Education and Physical Education journals listed on Web-Qualis (2013-2016), classified from A1 to B5 available online, between 2010 to 2019. 81 studies were found on this theme. Curricula, pedagogical proposals and teaching experiences are being produced by Physical Education teachers who work in this schooling cycle from multiple manifestations of body culture, collective work and respect for children's knowledge. These teachers still face challenges that originate in college and are perpetuated in teacher education.

Keywords: Systematic review. Education. Early Childhood Education. Physical Education.

Resumén: Esta investigación tuvo como objetivo analizar publicaciones científicas sobre Educación Física Escolar en Educación Infantil. Se realizó una revisión sistemática en todas las revistas de Educación y Educación Física enumeradas en Web-Qualis (2013-2016), clasificadas de A1 a B5 disponibles en línea, entre 2010 y 2019. Se encontraron 81 estudios sobre este tema. Los maestros de Educación Física que trabajan en este ciclo escolar elaboran planes de estudio, propuestas pedagógicas y experiencias de enseñanza a partir de múltiples manifestaciones de la cultura corporal, el trabajo colectivo y el respeto por el conocimiento de los niños. Estos maestros aún enfrentan desafíos que se originan en la educación inicial, se perpetúan en la educación continua y actúan.

Palavras clabe: Revisión sistemática. Educación. Educación Infantil. Educación Física.

Submetido em: 05-09-2020

Aceito em: 23-12-2020 
Educação física escolar na educação infantil: uma revisão sistemática

Uirá de Siqueira Farias - Daniel Teixeira Maldonado • Vinicius dos Santos Moreira • Elisabete dos

Santos Freire · Graciele Massoli Rodrigues

\section{Introdução}

Entender a criança da Educação Infantil (EI) como sujeito de direitos que se expressa por meio de diversas linguagens, brincadeiras, sentimentos, gestos, movimentos em dado contexto (SAYÃO, 2008) é um desafio para a Educação e a Educação Física Escolar (EFE). Na concepção de Sarmento (2013, p. 14), é necessário entender a criança como "ser-que-é", considerando a infância como categoria geracional, que possui sua própria forma, um ser completo, que tem sua voz, que vê o mundo com seus olhos e que se diferencia dos adultos (SARMENTO, 2013; QVORTRUP, 2010).

Na esteira dessa discussão sobre a EFE na El, tanto Vaz (2018) como Surdi, Melo e Kunz (2016) discutem a questão do corpo nos ambientes educacionais. A ideia de "corpos presos em carteiras, controlados e enfileirados" (SURDI; MELO; KUNZ, 2016, p. 460) são marcas da escola, limitando as possibilidades de interação e expressão.

Surdi, Melo e Kunz (2016) refletem ainda sobre a fragmentação dos processos de ensino, consequência da existência de disciplinas que cuidam dos aspectos cognitivos, intelectuais, afetivo-emocionais e do comportamento motor. Prevalece, dessa forma, a preocupação com questões relacionadas ao ler, escrever e calcular em detrimento das manifestações corporais e emocionais.

As crianças são seres artísticos, se expressam à sua maneira, criam, vivem o presente brincando, se-movimentam de várias formas, algo que se torna pura expressão de suas emoções. Quando as crianças brincam, interagem com o mundo construindo seu próprio repertório, doando-se por inteiro. Lidar com isso tem sido um desafio para a escola que possui tradicionalmente a função de apenas transmitir conhecimento (SURDI; MELO; KUNZ, 2016).

Por conta dessa realidade, um grande desafio está lançado para as aulas de Educação Física nesse ciclo de escolarização: deixar de carregar sua herança histórica associada apenas à ginástica 
Educação física escolar na educação infantil: uma revisão sistemática

Uirá de Siqueira Farias - Daniel Teixeira Maldonado • Vinicius dos Santos Moreira • Elisabete dos Santos Freire • Graciele Massoli Rodrigues

recreativa, ao desenvolvimento muscular, a psicomotricidade, ao tempo de descanso das atividades ditas sérias e ao tempo de recompensa por ter desenvolvido as lições de sala (ROCHA, 2011). A área precisa romper com tais sinônimos de aula para avançar no debate sobre como considerar as crianças como sujeitos de direitos.

A pesquisa científica pode ter um papel relevante para a reflexão e a construção de práticas pedagógicas que considerem as crianças como seres culturais e produtores de conhecimento (FORMOSINHO; FORMOSINHO, 2019). Diversos autores e autoras (SAYÃO, 1996; AYOUB, 2001; ROCHA, 2011; MELLO et al., 2016; MARTINS, 2018; BONFIETTI, et al., 2019) têm evidenciado que a EFE na El é um tema de pesquisa recente, sendo imprescindível ampliar o número de estudos.

A investigação sobre a produção científica já existente tem o importante papel de identificar os caminhos trilhados pelas pesquisas já realizadas, identificando algumas de suas características epistemológicas ou metodológicas. Esses estudos, ao apontarem os avanços e as lacunas existentes na investigação sobre um determinado objeto de estudo, permitem a elaboração de pesquisas que contribuam para o desenvolvimento da área.

Farias et al. (2019) afirmam que é possível perceber um crescimento no número das pesquisas realizadas nas últimas décadas a partir de uma revisão que analisou a produção científica sobre a EFE na El, desenvolvida em programas de pós-graduação em Educação Física e Educação. Os autores e autoras identificaram 147 teses e dissertações produzidas, sendo que a maioria delas focalizou o diagnóstico da realidade.

Ainda é possível encontrar alguns estudos que analisaram a produção científica sobre essa temática (MOURA; COSTA; ANTUNES; 2016; MELLO et al., 2012; MARTINS; BARBOSA; MELLO, 2018). Todavia, essas investigações possuem uma limitação em comum, que foi restringir sua base de pesquisa a periódicos dos estratos superiores do Web-Qualis. 
Educação física escolar na educação infantil: uma revisão sistemática

Uirá de Siqueira Farias • Daniel Teixeira Maldonado • Vinicius dos Santos Moreira • Elisabete dos Santos Freire • Graciele Massoli Rodrigues

Acreditamos que ampliar o número de revistas analisadas para compreender a realidade da Educação Física no cotidiano da escola, como fizeram Bracht et al. (2011) e Maldonado, Silva e Miranda (2014), permitirá a construção de um retrato mais fidedigno sobre a publicação que focaliza esse fenômeno.

Partindo desse pressuposto, o objetivo desta pesquisa foi analisar a publicação científica que tem como tema a EFE na EI em periódicos com diferentes classificações pela Coordenação de Aperfeiçoamento de Pessoal de Nível Superior (CAPES).

\section{Metodologia}

Optamos, nesta pesquisa, pela metodologia de revisão sistemática, que possui como característica investigar, reunir e sintetizar os resultados de estudos já desenvolvidos sobre uma determinada questão e apontar, dentro da temática, investigações que ainda necessitam ser realizadas (SAMPAIO; MANCINE, 2007). Para sua elaboração, seguimos os passos sugeridos por Garzon, Silva e Marques (2018), iniciando com uma pergunta direcionadora, seguida pela definição dos critérios de inclusão e exclusão para o levantamento dos estudos. A seguir, pesquisamos e elegemos os artigos nas bases de dados, analisamos os achados, e interpretamos e discutimos com a literatura da área os dados produzidos.

Para a seleção dos artigos nos inspiramos no estudo de Bracht et al. (2011). A partir dele, acessamos todas as revistas da Educação e da Educação Física listadas no Web-Qualis (2013-2016), classificadas de A1 até B5, disponíveis online, entre 2010 a 2019, nos meses de abril, maio, junho e julho de 2019, totalizando 96 revistas. Organizamos essa busca em duas etapas. Na primeira, analisamos nos sumários dos 96 periódicos (Educação e Educação Física) artigos que tratassem das aulas do componente curricular. Quando necessário, consultamos também os resumos dos artigos. Ao final dessa etapa, foram identificados 1763 artigos. Na segunda 
Educação física escolar na educação infantil: uma revisão sistemática

Uirá de Siqueira Farias • Daniel Teixeira Maldonado • Vinicius dos Santos Moreira • Elisabete dos

Santos Freire • Graciele Massoli Rodrigues

etapa de busca, dos 1763 artigos, selecionamos apenas estudos que tratavam do objeto desta pesquisa, chegando a um total de 81 artigos.

Para realizar a análise, interpretação e discussão das informações foram lidos os títulos, resumos e palavras-chave e categorizamos as temáticas encontradas com base em Lankshear e Knobel (2008), que recomendam a criação de pré-categorias que se tornarão categorias finais, possibilitando agrupar temáticas e, se necessário, realizar alterações para melhor compreensão do tema. As categorias foram produzidas a partir do estudo realizado por Farias et al. (2019).

\section{Análise e discussão dos resultados}

Mesmo com o evidente aumento no número de estudos sobre a Educação Física no Ensino Infantil, ainda consideramos pequena a produção de conhecimento nesse tema, já que apenas 4,65\% do total de estudos encontrados sobre o ensino da Educação Física focalizam, especificamente, a primeira etapa da Educação Básica. Portanto, confirma-se os resultados apresentados por Moura, Costa e Antunes (2016) e Mello et al. (2012). Para esses autores e autoras, o aumento no número de professores e professoras atuando com crianças pequenas ainda não se reflete na produção acadêmica que versa sobre a inserção/intervenção do componente curricular nesse ciclo de escolarização.

A maioria dos estudos encontrados foram publicados em periódicos categorizados em B2, B4 e B5 na classificação do WebQualis (2013-2016), como pode ser observado no Gráfico 1. 
Educação física escolar na educação infantil: uma revisão sistemática

Uirá de Siqueira Farias • Daniel Teixeira Maldonado • Vinicius dos Santos Moreira • Elisabete dos

Santos Freire - Graciele Massoli Rodrigues

\section{Gráfico 1 - Distribuição dos estudos levando em consideração Web-Qualis 2013-2016}

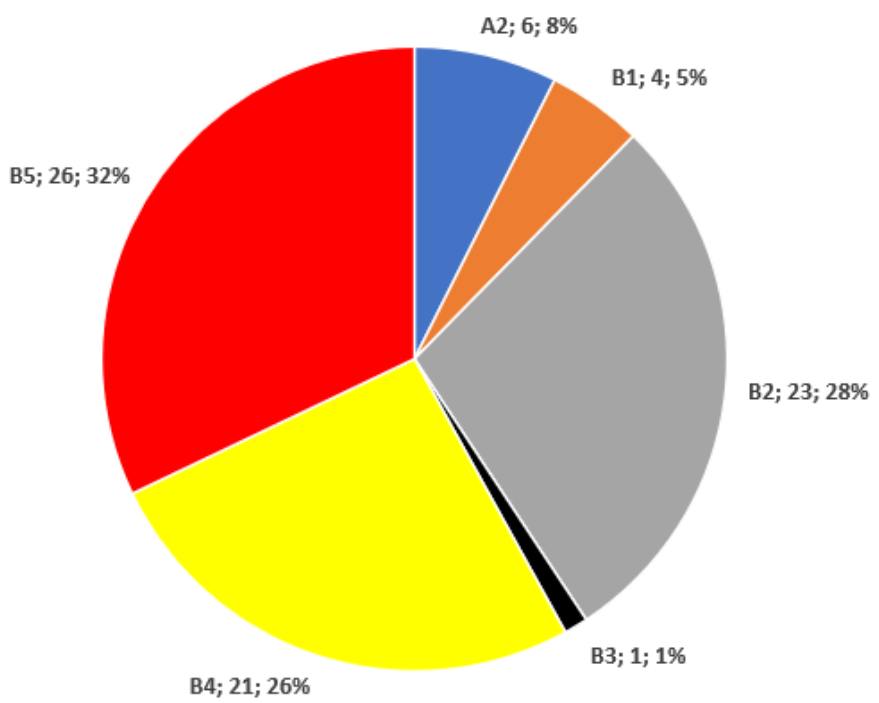

Fonte: Elaborado pelos autores e autoras

O Gráfico 2 demonstra as revistas científicas que mais publicaram pesquisas sobre essa temática. O periódico com mais estudos sobre o tema foi o Caderno de Formação, uma publicação do Colégio Brasileiro de Ciências do Esporte (CBCE) administrada pela Universidade Federal de Santa Catarina. Essa revista possui um número bem expressivo de artigos, contabilizando 22 manuscritos dos 81 encontrados. As três próximas revistas que possuem a maior quantidade de publicações sobre o tema foram a Motrivivência, com 11 pesquisas, um periódico que é organizado com o apoio da Universidade Federal de Santa Catarina, a Pensar a Prática, com 10 estudos, editorado pela Universidade Federal de Goiás, e a Movimento, com 6 artigos, mantida pela Universidade Federal do Rio Grande do Sul. 
Educação física escolar na educação infantil: uma revisão sistemática

Uirá de Siqueira Farias • Daniel Teixeira Maldonado • Vinicius dos Santos Moreira • Elisabete dos Santos Freire $\cdot$ Graciele Massoli Rodrigues

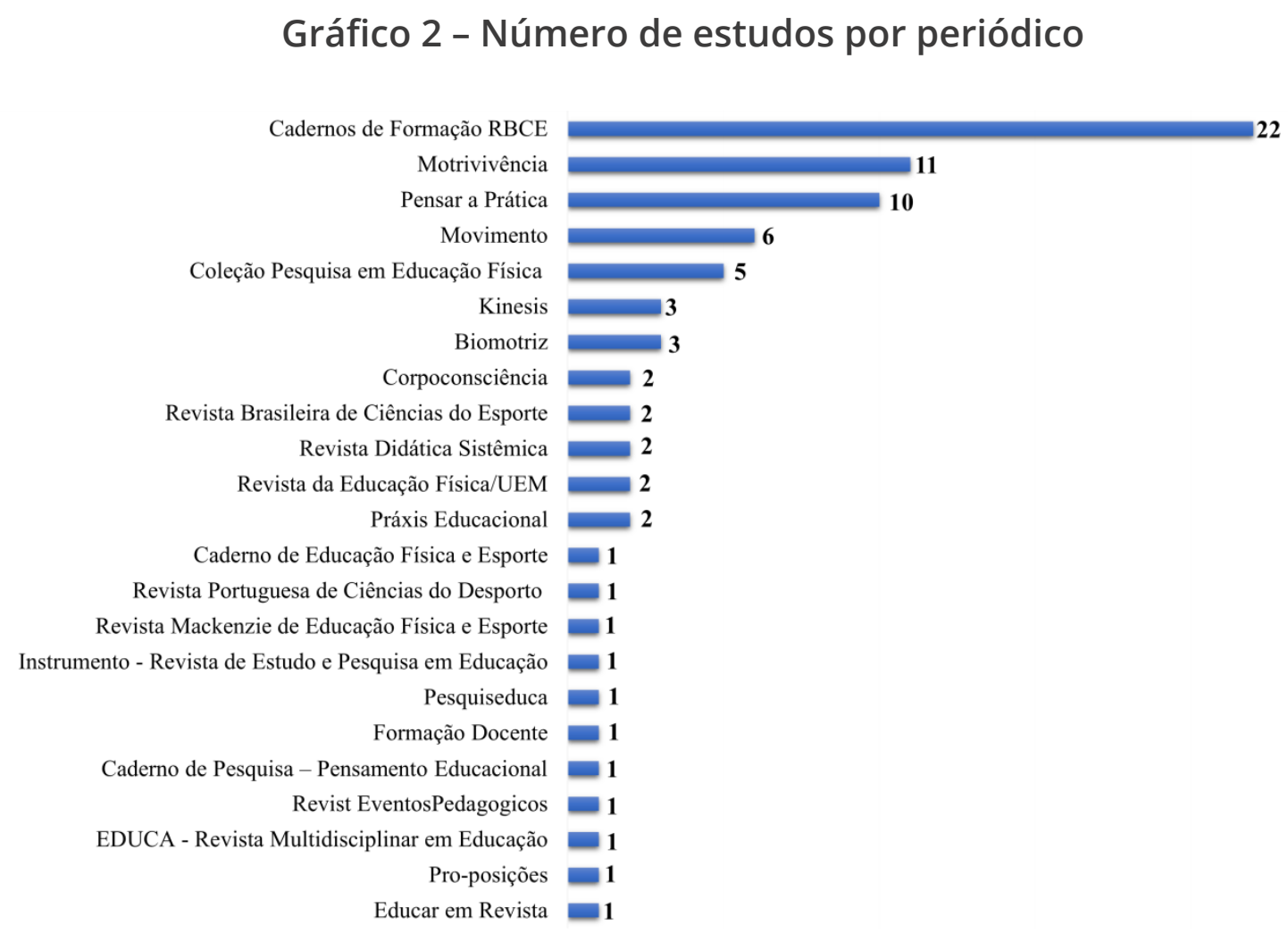

Fonte: Elaborado pelos autores e autoras.

Com exceção dos Cadernos de Formação $R B C E$, as revistas Motrivivência, Pensar a Prática e Movimento foram consideradas no estudo de Bracht et al. (2011) como aquelas que representam um número expressivo de estudos voltados para a Educação Física na escola. Vale ainda destacar que, embora essas três revistas estejam mais bem classificadas pelo Web-Qualis (2013-2016), os estudos sobre a EFE na El, em sua maior parte, ainda se encontram distribuídos entre os periódicos B2, B4 e B5. Esse dado pode estar associado a maior quantidade de revistas existentes com estratos inferiores. Em seguida, no Quadro 1, apresentamos todos os periódicos consultados e seus respectivos sites. 
Educação física escolar na educação infantil: uma revisão sistemática Uirá de Siqueira Farias • Daniel Teixeira Maldonado • Vinicius dos Santos Moreira • Elisabete dos Santos Freire • Graciele Massoli Rodrigues

\section{Quadro 1 - Revistas consultadas e seus sites}

\begin{tabular}{|c|c|}
\hline Revistas & Sites \\
\hline Cadernos de Formação & http://revista.cbce.org.br/index.php/cadernos \\
\hline Motrivivência & https://periodicos.ufsc.br/index.php/motrivivencia \\
\hline Pensar a Prática & https://www.revistas.ufg.br/index.php/fef \\
\hline Movimento & https://seer.ufrgs.br/Movimento \\
\hline Coleção Pesquisa em Educação Física & https://www.fontouraeditora.com.br/periodico/ \\
\hline Kinesis & https://periodicos.ufsm.br/kinesis \\
\hline Biomotriz & $\begin{array}{l}\text { https://revistaeletronica.unicruz.edu.br/index.php/ } \\
\text { BIOMOTRIZ/index }\end{array}$ \\
\hline Corpoconsciência & $\begin{array}{l}\text { https://periodicoscientificos.ufmt.br/ojs/index.php/ } \\
\text { corpoconsciencia }\end{array}$ \\
\hline $\begin{array}{l}\text { Revista Brasileira de Ciências do Es- } \\
\text { porte }\end{array}$ & $\begin{array}{l}\text { https://www.scielo.br/scielo.php?script=sci_serial\&pi- } \\
\underline{d}=0101-3289 \& \ln g=p t \& n r m=i s o\end{array}$ \\
\hline Revista Didática Sistêmica & https://periodicos.furg.br/redsis \\
\hline Revista da Educação Física/UEM & $\begin{array}{l}\text { http://www.periodicos.uem.br/ojs/index.php/RevEdu- } \\
\text { cFis }\end{array}$ \\
\hline Práxis Educacional & https://periodicos2.uesb.br/index.php/praxis/index \\
\hline Caderno de Educação Física e Esporte & $\begin{array}{l}\text { http://e-revista.unioeste.br/index.php/cadernoedfisi- } \\
\text { ca/index }\end{array}$ \\
\hline $\begin{array}{c}\text { Revista Portuguesa de Ciências do } \\
\text { Desporto }\end{array}$ & https://rpcd.fade.up.pt/entradaPT.html \\
\hline $\begin{array}{l}\text { Revista Mackenzie de Educação Física } \\
\text { e Esporte }\end{array}$ & http://editorarevistas.mackenzie.br/index.php/remef \\
\hline $\begin{array}{l}\text { Instrumento - Revista de Estudo e } \\
\text { Pesquisa em Educação }\end{array}$ & $\begin{array}{l}\text { https://periodicos.ufjf.br/index.php/revistainstrumen- } \\
\underline{\text { to }}\end{array}$ \\
\hline Pesquiseduca & $\begin{array}{l}\text { https://www.unisantos.br/editora/publicacoes-nacio- } \\
\text { nais/revista-pesquiseduca/ }\end{array}$ \\
\hline Formação Docente & https://revformacaodocente.com.br/index.php/rbpfp \\
\hline $\begin{array}{c}\text { Caderno de Pesquisa - Pensamento } \\
\text { Educacional }\end{array}$ & https://interin.utp.br/index.php/a/index \\
\hline Revista Eventos Pedagógicos & $\begin{array}{l}\text { http://sinop.unemat.br/projetos/revista/index.php/ } \\
\text { eventos }\end{array}$ \\
\hline $\begin{array}{l}\text { EDUCA - Revista Multidisciplinar em } \\
\text { Educação }\end{array}$ & https://www.periodicos.unir.br/index.php/EDUCA \\
\hline Pro-posições & $\begin{array}{l}\text { https://www.scielo.br/scielo.php?script=sci_serial\&pi- } \\
\underline{d=0103-7307 \& l n g=p t \& n r m=1}\end{array}$ \\
\hline Educar em Revista & https://revistas.ufpr.br/educar \\
\hline
\end{tabular}

Fonte: Elaborado pelos autores e autoras.

O Gráfico 3 apresenta a publicação temporal dos estudos que abordam a temática das aulas de Educação Física na primeira etapa da Educação Básica. Ao comparar a nossa análise com a 
Educação física escolar na educação infantil: uma revisão sistemática

Uirá de Siqueira Farias • Daniel Teixeira Maldonado • Vinicius dos Santos Moreira • Elisabete dos

Santos Freire • Graciele Massoli Rodrigues

pesquisa de Moura, Costa e Antunes (2016), foi possível perceber um aumento de mais de $50 \%$ de pesquisas sobre o referido tema entre 2010 e 2019, sendo o ponto de maior publicação em 2018, com 16 trabalhos. Esse dado pode demonstrar que mais pesquisadores e pesquisadoras têm se interessado em contribuir com as discussões que tangem o tema, principalmente por conta da Lei de Diretrizes e Bases da Educação (LDB) (BRASIL, 1996), que coloca a El compondo a Educação Básica; a Lei do Piso Salarial (BRASIL, 2008), que força os municípios a ajustarem os tempos de formações dos/das docentes, trazendo como opção a inserção dos especialistas nesse ciclo de escolarização; assim como as Diretrizes Curriculares Nacionais Gerais da Educação Básica (BRASIL, 2013) e a Base Nacional Comum Curricular (BRASIL, 2017), ambos documentos legais, fornecem elementos que servem para fortalecer esse debate, fato que pode ser observados nos estudos de Mello et al. (2016), Martins (2018), Martins e Mello (2019) e Bonfiette et al. (2019).

Outro ponto que pode ser levantado é o surgimento de grupos de pesquisas em algumas partes do país dedicados ao estudo da El, fato apontado no estudo de Farias et al. (2019), além do interesse de pesquisadores/as que ingressam em programas de mestrado e doutorado que pesquisam essa temática.

Salientamos que a brusca queda de estudos expressa no Gráfico 3, entre 2018 e 2019 se deu pelo recorte realizado, pois visitamos os periódicos somente até julho de 2019. Esse fato é importante de ser citado, pois várias revistas ainda não tinham disponibilizado todos os volumes de forma online, inviabilizando a ampliação de nossa análise para o restante do ano de 2019. 
Educação física escolar na educação infantil: uma revisão sistemática

Uirá de Siqueira Farias • Daniel Teixeira Maldonado • Vinicius dos Santos Moreira • Elisabete dos

Santos Freire $\cdot$ Graciele Massoli Rodrigues

\section{Gráfico 3 - Distribuição temporal das publicações nessa década}

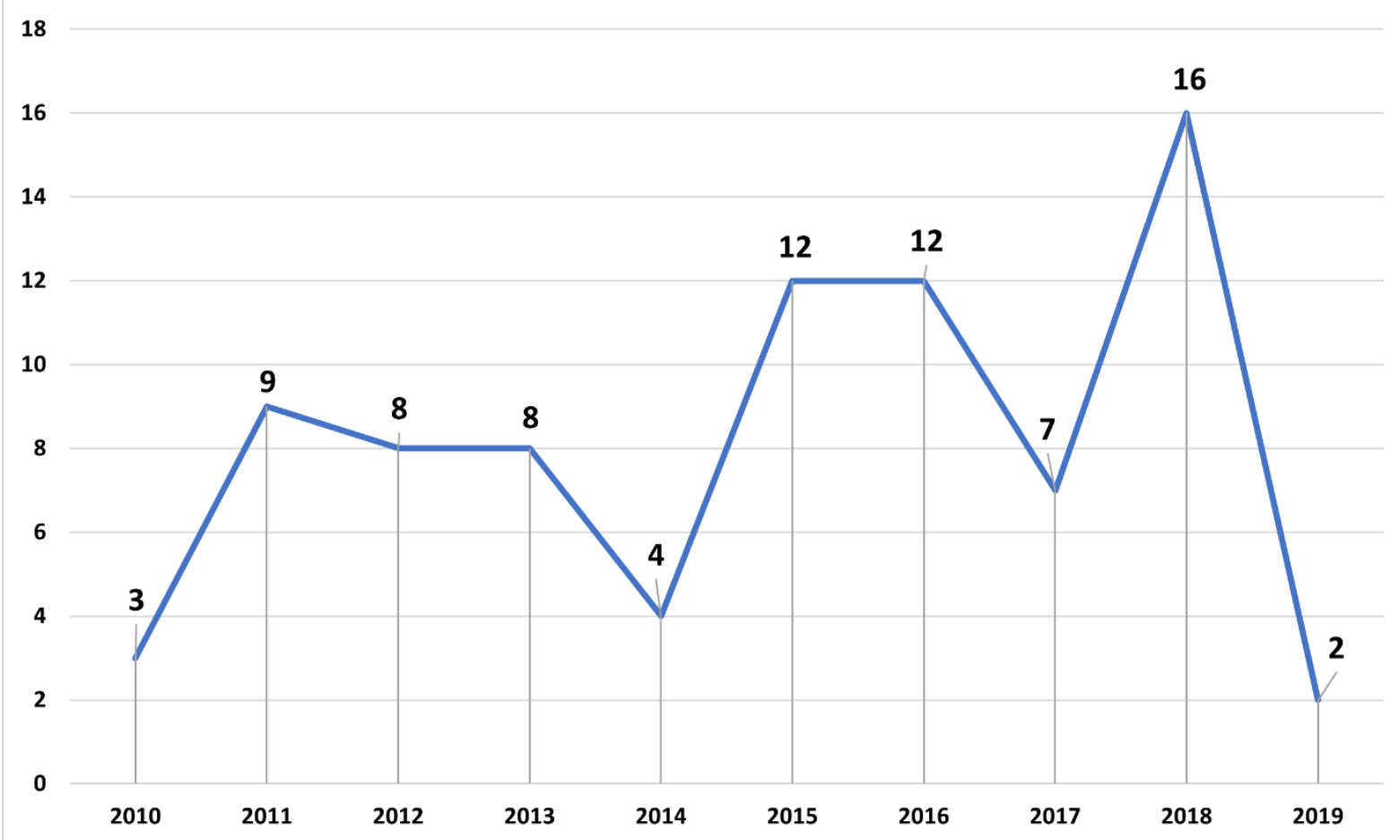

Fonte: Elaborado pelos autores e autoras.

Temas produzidos pelas pesquisas sobre a educação física escolar na educação infantil

No intuito de trazer uma análise mais qualitativa de nosso levantamento, procuramos categorizar os temas dos estudos encontrados, mostrando as temáticas discutidas nas pesquisas analisadas. 
Educação física escolar na educação infantil: uma revisão sistemática

Uirá de Siqueira Farias • Daniel Teixeira Maldonado • Vinicius dos Santos Moreira • Elisabete dos

Santos Freire • Graciele Massoli Rodrigues

Quadro 2 - Distribuição dos temas dos estudos por categorias de análise

\begin{tabular}{|c|c|}
\hline Categorias & Temas discutidos nos estudos \\
\hline $\begin{array}{c}\text { Formação Inicial, } \\
\text { Continuada e } \\
\text { Identidade Docente }\end{array}$ & $\begin{array}{l}\text { Curriculo da Universidade; Ementas das disciplinas; Identidade } \\
\text { docente; Estágio supervisionado na EFE; Autoformação; } \\
\text { Autobiografia; Saberes docentes; Aç̃es docentes; Formação inicial } \\
\text { com o PIBID; Atletismo e PIBID; Experiências no estágio } \\
\text { supervisionado; Experiências no estágio supervisionado - O circo; } \\
\text { Percepção sobre danças na Formação inicial. }\end{array}$ \\
\hline $\begin{array}{l}\text { Processo de Inserção } \\
\text { e Valorização da EFE } \\
\text { na EI }\end{array}$ & $\begin{array}{l}\text { Representação Social; A organização legal e pedagógica da EFE; } \\
\text { Legitimar e valorizar; Valorizar a inserção do professor especialista; } \\
\text { Cultura corporal como sistematizadora da linguagem corporal; A } \\
\text { inserção da EFE na EI; Desafios e possibilidades da EFE na EI; } \\
\text { Relevância da EFE na EI; Valorização do conhecimento corporal; } \\
\text { Conhecimento produzido sobre EFE. }\end{array}$ \\
\hline $\begin{array}{l}\text { Curriculo, Propostas } \\
\text { Pedagógicas e } \\
\text { Interdisciplinariedade }\end{array}$ & $\begin{array}{l}\text { Currículo da Escola; Trabalho com projetos; Projeto Articulador; } \\
\text { BNCC; Concepções de desenvolvimento humano; Proposta } \\
\text { interdisciplinar; Pedagogia histórico-critica e a psicologia histórico- } \\
\text { cultural; Currículo praticado; Avaliação da EFE na EI; Organização da } \\
\text { ação pedagógica; A EFE em dois paises; Transição da EI para o Ensino } \\
\text { Fundamental I; Teoria Histórico-Cultural, Teoria Histórico Crítica e } \\
\text { Pedagogia Critico-Superadora; Educação ambiental e EFE; Discutindo } \\
\text { o movimento na rotina escolar. }\end{array}$ \\
\hline $\begin{array}{c}\text { Relato de Práticas } \\
\text { Pedagógicas da EFE } \\
\text { na EI }\end{array}$ & $\begin{array}{l}\text { Brincadeiras Lúdico-agressivas na EI; Brincadeiras sob o olhar critico; } \\
\text { Brincadeiras significativas; Lúdico na EFE na EI; O brincar no } \\
\text { processo educativo; Proposta interdisciplinar com circo; Ação } \\
\text { pedagógica; Concepção de infância e EFE; Práticas corporais e EFE; } \\
\text { Inclusão; Esporte; Dança; Ginástica; Circo; Autoria coletiva e poética; } \\
\text { Crianças como protagonistas; As crianças, parceiros nos processos } \\
\text { comunicativos; Multicuturalismo crítico; Visita a praia; Literatura } \\
\text { Infantil - Faz de conta; Experiências de Ensino; Testes de equilibrio; } \\
\text { Efeitos de um programa psicomotor; Aprendizagem motora na EI; } \\
\text { Documentaçăo pedagógica de EFE na EI; As diferentes Infăncias. }\end{array}$ \\
\hline
\end{tabular}

Fonte: Elaborado pelos autores e autoras

Na categoria Formação Inicial, Continuada e Identidade Docente, procuramos agrupar estudos que apresentassem temas referentes ao estágio supervisionado, à autoformação e à construção da identidade docente, chegando a um total de 18 pesquisas. Essas análises apontam para importantes elementos que mostram o quanto os docentes da formação inicial, tanto em Pedagogia como em Educação Física, ainda necessitam repensar a maneira como tratam as discussões que envolvem as crianças, ou seja, é 
Educação física escolar na educação infantil: uma revisão sistemática

Uirá de Siqueira Farias - Daniel Teixeira Maldonado • Vinicius dos Santos Moreira • Elisabete dos Santos Freire • Graciele Massoli Rodrigues

necessário que esse processo formativo acompanhe os avanços que tanto a sociologia como a pedagogia da infância têm apresentado (SARMENTO, 2013; FORMOSINHO; PASCAL, 2019).

Alguns motivos têm impulsionado esse interesse, como a defasagem nos cursos de formação inicial em Pedagogia de temas relacionados à Educação Física, causando dificuldades de atuação por parte das professoras pedagogas ou generalistas (AYOUB, 2005), ou quando são tratados de forma reducionista, reforçando dicotomias. Esse reducionismo tem sido debatido por Bracht (1999), Sayão (2008) e Vaz (2018) como uma visão da tradição racionalista ocidental, onde o intelectual trata-se de uma esfera de superioridade sobre o corpo. "O corpo deve servir. O sujeito é sempre razão, ele (o corpo) é sempre objeto; a emancipação é identificada com a racionalidade da qual o corpo estava, por definição, excluído" (BRACHT, 1999, p. 70).

Longo e Xavier (2017) evidenciaram como é a formação dos professores e professoras nos cursos de Pedagogia e Educação Física que atuarão na El com o componente curricular. O trabalho avaliou os currículos, as ementas e realizou entrevistas com alunos, concluindo que não existe nesses cursos de formação inicial um aprofundamento mais denso sobre as práticas corporais, fato que causa despreparo e insegurança nos futuros docentes.

Quando o assunto foi identidade docente, dois estudos (RODRIGUES; FIGUEIREDO; 2011; RODRIGUES; FIGUEIREDO; ANDRADE FILHO, 2012) discutiram com mais profundidade esse tema. As pesquisadoras e o pesquisador trazem um debate que leva em consideração a trajetória de vida dos professores de Educação Física que atuam na El para mostrar que as identidades docentes sofrem influências diversas, que habitam as relações entre a organização da instituição, a relação entre adultos e crianças, além dos campos familiares, políticos e sociais. Ainda ressaltam a importância de ouvir e verificar o dia a dia dos/das profissionais que atuam na escola para de fato reunir esforços para compreender a complexidade de constituição das suas identidades profissionais. 
Educação física escolar na educação infantil: uma revisão sistemática

Uirá de Siqueira Farias • Daniel Teixeira Maldonado • Vinicius dos Santos Moreira • Elisabete dos

Santos Freire • Graciele Massoli Rodrigues

Outro achado importante em nosso levantamento foi encontrar artigos relacionados ao Programa Institucional de Bolsas de Iniciação à Docência (PIBID). Esses estudos têm explicitado como esse tipo de investimento pode promover uma formação inicial mais potente. Um exemplo dessas pesquisas foi apresentado por Floriano e Pereira (2018). Por meio do estágio supervisionado de Licenciatura em Educação Física da Universidade Federal de Santa Catarina, experiências riquíssimas de estudantes com o tema circo nas aulas de Educação Física na El foram relatadas. Nesse trabalho foi possível perceber uma prática pedagógica que leva em consideração um projeto de escola, no qual o componente curricular deve estar inserido nos vários momentos da dinâmica institucional, respeitando o tempo das crianças, ou seja, a atuação deve considerar a recepção dos educandos, a alimentação, a higiene e a hora do sono.

Vaz (2018) indica que na formação inicial em Educação Física a infância tem sido tratada, mas a forma como é debatida vem desconsiderando os conhecimentos provenientes das pesquisas que tratam da cultura.

O tratamento do tema parece não fazer justiça aos conhecimentos trazidos pelos estudos da cultura, restringindo-se, no mais das vezes, aos aspectos do crescimento e desenvolvimento das crianças, diminuindo-as como sujeitos. Prevalece ainda uma visão uniforme de criança, baseada nas capacidades físicas, nas preocupações com possíveis "correções" de habilidades motoras, em uma generalização abstrata do ideal de infância. (VAZ, 2018, p. 49).

A segunda categoria, intitulada Processo de Inserção e Valorização da EFE na El, reúne 19 pesquisas que procuraram discutir a pertinência do componente curricular nesse ciclo de escolarização, além de compreender como a Educação Física vem sendo constituída e avaliada pelos demais agentes que compõem essas escolas. Nesse contexto, Rocha (2011) levanta a questão: como 
Educação física escolar na educação infantil: uma revisão sistemática

Uirá de Siqueira Farias - Daniel Teixeira Maldonado • Vinicius dos Santos Moreira • Elisabete dos Santos Freire • Graciele Massoli Rodrigues

deve ser a atuação dos docentes de EFE nessa etapa da Educação Básica? Na perspectiva dos autores essa atuação deve levar em consideração as especificidades das crianças de 0 a 5 anos para além de preceitos apenas biológicos.

O recente estudo de Martins e Mello (2019) apresentou uma análise dos documentos oficiais sobre a El, ajudando a compreender o processo de mutação que essa primeira fase da Educação Básica vem passando desde 1996, principalmente por conta da publicação da Lei de Diretrizes e Bases da Educação Nacional (LDB).

Mello et al. (2012b) também discutiram as representações sociais que professores e professoras que atuam na El possuem das aulas de Educação Física. Assim, os autores mencionam que o componente curricular ainda fica marcado pelo momento de descanso das professoras regentes e como auxiliar de outras necessidades pedagógicas da escola, além de não dialogar com a proposta educativa da respectiva rede de ensino e ser visto como um modelo pedagógico esportivizante.

O estudo de Braun (2016) demonstrou que as aulas da disciplina na cidade Lucas do Rio - MT têm sido realizadas por professoras com formação no magistério ou em Pedagogia. Após a análise de seus resultados, o autor evidenciou que as professoras declararam não ter conhecimentos suficientes para trabalhar com a linguagem corporal e, diante disso, elas privilegiam as linguagens oral e escrita. Esse fato é apresentado pelo pesquisador como elemento fundamental para justificar a presença do professor ou professora de Educação Física nesse ciclo de escolarização.

Estudos importantes têm consultado as professoras pedagogas, colocando para a área de Educação Física a necessidade de mais pesquisas nesse campo. Esse dado pode ser corroborado com o estudo de Ehrenberg (2014), que a partir de entrevistas com docentes formadas em Pedagogia, evidenciou que as práticas corporais são contempladas por elas, mas não sob o nome de Educação Física. Um dado importante citado no estudo é o fato do esporte ser considerado como base das aulas, levando-as a fazer diversas críticas à função social do componente curricular. 
Educação física escolar na educação infantil: uma revisão sistemática

Uirá de Siqueira Farias - Daniel Teixeira Maldonado • Vinicius dos Santos Moreira • Elisabete dos Santos Freire • Graciele Massoli Rodrigues

Já o argumento que tem sido questionado é a presença da Educação Física na El atrelando-a exatamente aos especialistas, ou seja, é a questão de se inserir as disciplinas na organização das escolas (SOUZA, 2019). Preocupação essa que já foi salientada por Sayão (1999) e Ayoub (2001), ressaltando a necessidade de se pensar no trabalho pedagógico das pessoas que irão atuar com os estudantes e não nas disciplinas, ou seja, é uma questão de concepção, de se trabalhar em prol de um projeto para a formação integral das crianças.

A terceira categoria, nomeada Currículo, Propostas pedagógicas e Interdisciplinares, reuniu 21 pesquisas que trataram os temas curriculares, tipos de propostas pedagógicas e iniciativas interdisciplinares.

Corsi, Marco e Ontañón (2018) trazem a discussão de uma proposta pedagógica interdisciplinar elaborada entre pedagogas e professores de Educação Física que envolveu a arte, a cultura, o movimento, a expressão e o lúdico, utilizando o tema circo como pano de fundo. As pesquisadoras e o pesquisador entendem que uma proposta interdisciplinar para as crianças pequenas deve visualizar a educação integral, compreendendo os conhecimentos como interativos e interdependentes entre professoras generalistas e especialistas.

Mello et al. (2018) também discutiram a articulação pedagógica da Educação Física nesse ciclo de escolaridade com outras áreas do conhecimento. Por meio de entrevistas com cinco docentes, identificaram que existe dificuldade e desafios que impedem a construção coletiva dos planejamentos, como tempo e espaços de formação coletiva para esse fim e a representação que as professoras pedagogas ainda possuem do componente curricular. Todavia, os autores ressaltam a importância de um projeto institucional para minimizar o distanciamento entre as áreas de conhecimento.

Os estudos classificados nessa categoria trazem discussões extremamente importantes, que mostram como alguns professores e professoras de Educação Física estão atuando nas escolas da 
Educação física escolar na educação infantil: uma revisão sistemática

Uirá de Siqueira Farias - Daniel Teixeira Maldonado • Vinicius dos Santos Moreira • Elisabete dos

Santos Freire • Graciele Massoli Rodrigues

primeira etapa da Educação Básica, sendo que alguns vêm estabelecendo parcerias, outros apresentando dificuldades, mas acima de tudo produzindo conhecimento para mais pesquisas com o interesse nesse tema.

A quarta e última categoria, Relato de Práticas Pedagógicas da EFE na El, agrupou 23 estudos que trataram diretamente da prática pedagógica na escola. Essa categoria revelou que além dos estudos que focam nas análises motoras (que contabilizaram três estudos), foi possível perceber um crescimento das análises que vão além desse tipo de discussão. Como exemplo, Mello et al. (2014) evidenciaram a produção de saberes no cotidiano escolar, mencionando que os desafios da intervenção se relacionam ao comportamento infantil e às rotinas impostas pelas instituições. Quando analisadas as possibilidades pedagógicas, o estudo demonstrou que existe um esforço dos indivíduos consultados para conceber a criança como sujeito de direitos e que a centralidade das ações didáticas está nas brincadeiras e nos jogos.

O estudo de Souza e Neira (2015) apresentou reflexões sobre os pressupostos do multiculturalismo crítico para as aulas na El, elucidando o patrimônio cultural corporal de uma comunidade de Aracajú - SE junto às crianças. A autora e o autor salientam que a professora pôde ressignificar sua atuação pedagógica a partir da realização de um planejamento que levou em consideração os saberes daquela comunidade escolar.

A pesquisa de Goulart (2018) apresentou a literatura de "faz de conta" nas aulas de Educação Física, um relato de experiência que ocorreu com turmas de dois a cinco anos do Município de Serra ES. Os autores apontaram que a literatura infantil pode ser uma possibilidade pedagógica para as aulas do componente curricular, potencializando o processo de ensino e aprendizagem de forma criativa, desafiadora e enriquecedora para as crianças.

Consideramos que os estudos que tratam de relatos de práticas pedagógicas têm avançado em discussões que envolvem olhares diferenciados para as crianças, além de considerarmos 
Educação física escolar na educação infantil: uma revisão sistemática Uirá de Siqueira Farias • Daniel Teixeira Maldonado • Vinicius dos Santos Moreira • Elisabete dos Santos Freire - Graciele Massoli Rodrigues

esse achado de grande importância para área, uma vez que essas publicações demonstram que existem professores e professoras, intelectuais da realidade escolar em algumas regiões do país, produzindo práticas pedagógicas significativas da EFE. É possível verificar com base nos estudos do Quadro 3 temas como a inclusão, o esporte, as crianças como autoras da significação das aulas, a ginástica, o circo, a dança e as discussões com a sociologia da infância.

\section{Quadro 3 - Alguns exemplos de estudos da categoria Relato de Práticas Pedagógicas da EFE na EI}

\begin{tabular}{|c|c|c|c|}
\hline Revistas & Ano & Autores/as & Títulos \\
\hline Pensar a Prática & 2010 & $\begin{array}{l}\text { Atos Prinz Falkenbach; } \\
\text { Elaine Regina Lopes. }\end{array}$ & $\begin{array}{c}\text { Professores de Educação Física } \\
\text { diante da inclusão de alunos com } \\
\text { deficiência visual }\end{array}$ \\
\hline Motrivivência & 2011 & $\begin{array}{c}\text { Rubens Machado; Bruno } \\
\text { Fagundes; Fabiano We- } \\
\text { ber Da Silva. }\end{array}$ & $\begin{array}{c}\text { As crianças como autoras da signifi- } \\
\text { cação da Educação Física }\end{array}$ \\
\hline Cadernos de Formação & 2011 & $\begin{array}{c}\text { Michelle Cristina Gou- } \\
\text { lart. }\end{array}$ & $\begin{array}{c}\text { Ginástica, circo e dança: um relato } \\
\text { da Educação Física na Educação } \\
\text { Infantil }\end{array}$ \\
\hline Práxis Educacional & 2012 & $\begin{array}{c}\text { Andréa Regina Fonseca } \\
\text { Silveira. }\end{array}$ & $\begin{array}{c}\text { "Faz melão, faz melancia”: um relato } \\
\text { sobre dança, Educação Infantil e } \\
\text { Educação Física }\end{array}$ \\
\hline Cadernos de Formação & 2012 & $\begin{array}{l}\text { Victor José Machado De } \\
\text { Oliveira; David Gomes } \\
\text { Martins. }\end{array}$ & $\begin{array}{l}\text { Itinerário de uma intervenção com } \\
\text { crianças: um diálogo no/com o coti- } \\
\text { diano e a sociologia da infância }\end{array}$ \\
\hline Cadernos de Formação & 2012 & $\begin{array}{c}\text { Adriana Maria Pereira } \\
\text { Wendhausen. }\end{array}$ & $\begin{array}{l}\text { Conteúdos, linguagens e possibili- } \\
\text { dades: o relato de uma proposta da } \\
\text { Educação Física na Educação Infantil }\end{array}$ \\
\hline Cadernos de Formação & 2013 & $\begin{array}{c}\text { Victor José Machado De } \\
\text { Oliveira }\end{array}$ & $\begin{array}{c}\text { No foco da educação para a susten- } \\
\text { tabilidade: experiências da Educa- } \\
\text { ção Física no CMEI Professora Dilza } \\
\text { Maria De Lima }\end{array}$ \\
\hline Cadernos de Formação & 2013 & $\begin{array}{c}\text { Andréa Regina Fonseca } \\
\text { Silveira }\end{array}$ & $\begin{array}{c}\text { Balançando, remexendo: experiên- } \\
\text { cias pedagógicas de um Grupo } 1 \\
\text { (Quatro Meses A Um Ano) na Educa- } \\
\text { ção Física }\end{array}$ \\
\hline $\begin{array}{c}\text { Coleção Pesquisa em } \\
\text { Educação Física }\end{array}$ & 2013 & $\begin{array}{c}\text { Amanda Barbara Honó- } \\
\text { rio De Oliveira; Pierre } \\
\text { Normando Gomes-Da- } \\
\text {-Silva; Alexandre Sérgio } \\
\text { Silva; Danielle Menezes } \\
\text { De Oliveira. }\end{array}$ & $\begin{array}{l}\text { Equilíbrio e inteligência expressiva: } \\
\text { uma análise na Educação Física } \\
\text { Infantil }\end{array}$ \\
\hline
\end{tabular}


Educação física escolar na educação infantil: uma revisão sistemática Uirá de Siqueira Farias • Daniel Teixeira Maldonado • Vinicius dos Santos Moreira • Elisabete dos Santos Freire - Graciele Massoli Rodrigues

\begin{tabular}{|c|c|c|c|}
\hline $\begin{array}{l}\text { Revista Brasileira de } \\
\text { Ciências do Esporte }\end{array}$ & 2014 & $\begin{array}{l}\text { André Da Silva Mello; } \\
\text { Wagner dos Santos; } \\
\text { Marcos Vinícius Klippel; } \\
\text { Amanda de Pianti Rosa; } \\
\text { Sebastião Josué Votre. }\end{array}$ & $\begin{array}{c}\text { Educação Física na Educação Infan- } \\
\text { til: produçãao de saberes no cotidia- } \\
\text { no escolar }\end{array}$ \\
\hline Corpoconsciência & 2015 & $\begin{array}{l}\text { Luciana Dias De Oliveira; } \\
\text { Elaine Prodócimo. }\end{array}$ & $\begin{array}{c}\text { A prática do professor de Educação } \\
\text { Física na Educação Infantil }\end{array}$ \\
\hline Cadernos de Formação & 2015 & $\begin{array}{l}\text { Marília Menezes Nasci- } \\
\text { mento Souza; Marcos } \\
\text { Garcia Neira. }\end{array}$ & $\begin{array}{l}\text { Tematizando a cultura corporal na } \\
\text { Educação Infantil: uma experiência } \\
\text { multiculturalmente orientada }\end{array}$ \\
\hline Cadernos de Formação & 2015 & $\begin{array}{l}\text { Renata Marques Rodri- } \\
\text { gues }\end{array}$ & $\begin{array}{c}\text { Conhecendo o mundo na escola: } \\
\text { uma intervenção com a dança na } \\
\text { Educação Infantil }\end{array}$ \\
\hline Cadernos de Formação & 2015 & André Delazari Tristão. & $\begin{array}{l}\text { "A Educação Física vai à praia": } \\
\text { relato e reflexões de um projeto na } \\
\text { Educação Infantil }\end{array}$ \\
\hline $\begin{array}{l}\text { Revista da Educação } \\
\text { Física/UEM }\end{array}$ & 2017 & $\begin{array}{l}\text { Marciel Barcelos; Wag- } \\
\text { ner Santos; Amarílio } \\
\text { Ferreira Neto. }\end{array}$ & $\begin{array}{l}\text { Aprender na Educação Física: diálo- } \\
\text { gos com as crianças e a professora }\end{array}$ \\
\hline Cadernos de Formação & 2018 & $\begin{array}{l}\text { Milainy Ludmila Santos } \\
\text { Goulart }\end{array}$ & $\begin{array}{l}\text { Viajando no mundo da literatura in- } \\
\text { fantil: uma experiência pedagógica } \\
\text { nas aulas de Educação Física }\end{array}$ \\
\hline Biomotriz & 2018 & $\begin{array}{c}\text { Marcílio Dias Holanda; } \\
\text { Liara Santana Sales; } \\
\text { Robert Maurício Oliveira } \\
\text { Araújo; Antônio Carlos } \\
\text { Leal Cortez }\end{array}$ & $\begin{array}{c}\text { Prática pedagógica do profissional } \\
\text { de Educação Física no Ensino Infan- } \\
\text { til em escolas da rede privada de } \\
\text { uma capital brasileira }\end{array}$ \\
\hline Biomotriz & 2019 & $\begin{array}{c}\text { Fioravante Corrêa Da } \\
\text { Rocha; Jônatas Da Costa } \\
\text { Brasil De Borba; André } \\
\text { Osvaldo Furtado Da } \\
\text { Silva; Elisandro Schultz } \\
\text { Wittizorecki }\end{array}$ & $\begin{array}{l}\text { A Educação Física na Educação } \\
\text { Infantil: retratos da prática pedagó- } \\
\text { gica diante de diferentes infâncias }\end{array}$ \\
\hline
\end{tabular}

Fonte: Elaborado pelos autores e autoras.

Ao olhar para essas quatro categorias, é possível perceber que existem alguns distanciamentos. Os estudos que envolvem a formação inicial e continuada e as pesquisas que trataram do processo de inserção e valorização da EFE na Educação Infantil demonstram que ainda existe um distanciamento das discussões mais contemporâneas sobre as crianças como seres de direitos e que produzem cultura. Esse fato promove tanto a dificuldade de atuação dos/das docentes ao atender as crianças como gera nos agentes que trabalham nessas instituições de ensino a dificulda- 
Educação física escolar na educação infantil: uma revisão sistemática

Uirá de Siqueira Farias • Daniel Teixeira Maldonado • Vinicius dos Santos Moreira • Elisabete dos Santos Freire • Graciele Massoli Rodrigues

de em promover um projeto pedagógico interdisciplinar unificado que atenda de fato as características das crianças.

Ao analisar as categorias que trataram do currículo, das propostas educativas e dos relatos de práticas pedagógicas, visualizamos que os/as diversos/diversas professores/ professoras têm construído uma prática político-pedagógica que se aproxima de um olhar mais sensível à cultura, ao contexto, ao conhecimento construído com as crianças e na direção de respeitar seus direitos. São atuações pedagógicas com uma visão ampla de educação, em que o foco deve ser valorizar a criação, a fantasia, a expressão, o mundo das crianças como seres que produzem conhecimento nas relações que estabelecem com os diversos tempos e espaços de suas vidas.

Esses dois paralelos podem demonstrar reflexos de algo que Bracht (2015) salienta em uma de suas obras, que quanto mais perto as pesquisas estão dos critérios estabelecidos pela CAPES, as discussões ficam mais distantes das escolas.

Fortalecendo essa problemática, tanto Nóvoa (1999) quanto Charlot (2013) já apontavam que existe uma produção discursiva que deslegitima os professores e as professoras que atuam na Educação Básica como produtores de saberes e, em contraposição, legitima os grupos de especialistas como autoridades científicas, acarretando em valorização dos discursos e pobreza das práticas pedagógicas.

Nesta pesquisa isso se evidencia quando verificamos que as vozes de docentes que estão nas escolas aparecem nos seus relatos de experiências de práticas pedagógicas em revistas com uma qualificação menor no Web-Qualis (2013-2016), como, por exemplo, o periódico Caderno de Formação. Essas pesquisas têm demonstrado o que de fato está acontecendo nas aulas de Educação Física na Educação Básica. 


\section{Considerações finais}

Foi possível perceber, com base em nosso estudo, que as pesquisas que tratam da EFE na El de 2010 a 2019 tiveram um crescimento interessante e que podem contribuir para a área, uma vez que as discussões que envolvem essa temática ainda possuem muitas lacunas, como já apontavam Sayão (1999) e Ayoub (2001) há pelo menos duas décadas.

Respondendo à pergunta desta pesquisa, a produção do conhecimento analisada está organizada em quatro temas. São pesquisas divulgadas em diversos periódicos que têm debatido: 1) a formação inicial e continuada; 2) a inserção e legitimação do componente curricular nessa etapa da Educação Básica; 3) as propostas curriculares 4 ) e as práticas pedagógicas efetivadas na realidade escolar.

O fato de analisar revistas que não possuem uma boa avaliação nos critérios da CAPES permitiu perceber que estudos feitos por professores e professoras que vivem a realidade escolar, principalmente por meio de relatos de experiências, se encontram concentrados nesses periódicos. Portanto, o potencial desses/as docentes em produzir conhecimento, mesmo diante das dificuldades vivenciadas no cotidiano escolar, foram apontados neste trabalho de revisão integrativa.

Essa ressignificação pode ser observada com base na riqueza dos temas que vêm sendo estudados por pesquisadores e pesquisadoras em âmbito nacional; são discussões que permeiam os relatos de práticas pedagógicas efetivadas nas escolas, utilizando múltiplas manifestações da cultura corporal, como circo, danças, jogos e brincadeiras. Estudos que navegam pelos processos de inserção e valorização da Educação Física, refletindo sobre os motivos que podem ou não contribuir para a permanência do componente curricular nessa etapa da Educação Básica.

A partir dos resultados aqui apresentados, acreditamos que os estudos sobre a produção de conhecimento que focalizem a 
Educação física escolar na educação infantil: uma revisão sistemática

Uirá de Siqueira Farias • Daniel Teixeira Maldonado • Vinicius dos Santos Moreira • Elisabete dos

Santos Freire • Graciele Massoli Rodrigues

Educação Física nas escolas de modo geral não podem se limitar a analisar apenas as revistas de estratos superiores do Web-Qualis, uma vez que a maior parte das investigações sobre essa temática estão em periódicos classificados como B4 e B5, pois é neles que de fato as práticas pedagógicas dos docentes desse componente curricular aparecem.

Cientes da limitação de nossas análises, apresentamos um panorama que consideramos bem interessante no cenário das pesquisas que envolvem a EFE na El, principalmente os estudos que têm se debruçado em elementos como a cultura, a sociologia, os tempos e espaços pedagógicos, não ficando somente presos a análises motoras. Podemos dizer que já é notório os avanços, entretanto, é pertinente que mais investigações se aprofundem nessas discussões, principalmente aquelas que se materializam no dia a dia das escolas brasileiras.

\section{Referências}

AYOUB, Eliana. Reflexões sobre a Educação Física na Educação Infantil. Revista Paulista de Educação Física, São Paulo, v. Supl. 4, p. 56-60, 2001.

AYOUB, Eliana. Narrando experiências com a Educação Física na Educação Infantil. Revista Brasileira de Ciências do Esporte, Campinas, v. 26, n. 3, p. 143-158, maio 2005.

BONFIETTI, Priscila Errerias et al. O/A Professor/a de Educação Física na Educação Infantil. @mbienteeducação, São Paulo, v. 12, n. 1, p. 160-176, jan./abr. 2019.

BRACHT, Valter. A constituição das teorias pedagógicas da educação física. Cadernos Cedes, Campinas, v. 48, n. XIX, p. 69-88, ago. 1999.

BRACHT, Valter. Educação física, método científico e reificação. In: STIGGER, M. P. Educação Física + Humanas. Campinas: Autores Associados, 2015. p. 1-22. 
Educação física escolar na educação infantil: uma revisão sistemática

Uirá de Siqueira Farias - Daniel Teixeira Maldonado • Vinicius dos Santos Moreira • Elisabete dos Santos Freire • Graciele Massoli Rodrigues

BRACHT, Valter et al. A Educação Física Escolar como tema da produção do conhecimento nos periódicos da área no Brasil (19802010): parte I. Movimento, Porto Alegre, v. 17, n. 2, p. 11-34, abr./ jun. 2011.

BRASIL. 9394/96 - Lei de Diretrizes e Bases da Educação

Nacional (LDB). Ministério da Educação. Brasília. 1996.

Disponível em: http://www.planalto.gov.br/ccivil_03/leis/19394. htm. Acesso em: 20 jul. 2020.

BRASIL. Lei 11.738/2008 - Lei que Regulamenta o Piso Salarial Profissional Nacional para os profissionais do magistério público da Educação Básica. Conselho Nacional de Educação. Brasília. 2008. Disponível em: http://www.planalto.gov.br/ccivil_03/_ato2007-2010/2008/lei/111738.htm\#: :text=20\%200\%20 piso\%20salarial,modalidade\%20Normal\%2C\%20prevista\%20 no\%20art. Acesso em: 20 jul. 2020.

BRASIL. Diretrizes Curriculares Nacionais Gerais da Educação Básica. Brasília: Minitério da Educação. Secretaria de Educação Básica. Diretoria de Currículos e Educação Integral, 2013. Disponível em: http://portal.mec.gov.br/docman/julho-2013-pdf/ 13677-diretrizes-educacao-basica-2013-pdf/file. Acesso em: 20 jul. 2020.

BRASIL. Ministério da Educação. Base Nacional Comum Curricular (2017). Disponível em: http://basenacionalcomum. mec.gov.br/documento-curricular/. Acesso em: 20 jul. 2020.

BRAUN, Anderson Gustavo. Educação Física na Pré-escola: um espaço questionado. Revista Eventos Pedagógicos, Sinop - Mato Grosso, v. 7, n. 3, p. 1363-1364, ago./dez. 2016.

CHARLOT, Bernard. Da relação com o saber às práticas educativas. São Paulo: Cortez, 2013.

COORDENAÇÃO DE APERFEIÇOAMENTO DE PESSOAL DE NÍVEL SUPERIOR. Classificações de periódicos quadriênio 2013-2016. [S. I.]: CAPES, c2016. Disponível em: https://sucupira.capes.gov.br/ sucupira/public/consultas/coleta/veiculoPublicacaoQualis/listaConsultaGeralPeriodicos.jsf. Acesso em: 17 nov. 2020. 
Educação física escolar na educação infantil: uma revisão sistemática

Uirá de Siqueira Farias • Daniel Teixeira Maldonado • Vinicius dos Santos Moreira • Elisabete dos Santos Freire • Graciele Massoli Rodrigues

CORSI, Laís Marconato; MARCO, Ademir de; ONTAÑóN, Teresa. Educação Física na Educação Infantil: Proposta interdiciplinar de atividades circenses. Pensar a Prática, Goiânia, v. 21, n. 4, p. 865876, out./dez. 2018.

EHRENBERG, Mônica Caldas. A linguagem da cultura corporal sob o olhar de professores da educação infantil. Pro-posições, São Paulo, v. 25, n. 1, p. 181-198, jan./abr. 2014.

FARIAS, Uirá de Siqueira et al. Análise da produção do conhecimento sobre a Educação Física na Educação Infantil. Movimento, Porto Alegre, v. 25, p. 1-17, e25058, 2019.

FLORIANO, Thiago Adelino; PEREIRA, Breno Ferreira. O circo na Educação Infantil: um relato de experiência. Cadernos de Formação RBCE, Rio de Janeiro, v. 9, n. 1, p. 45-53, mar. 2018. FORMOSINHO, Júlia Oliveira; FORMOSINHO, João. Pedagogia-emParticipação: em busca de uma práxis holísitica. In: OLIVEIRAFORMOSINHO, J.; PASCAL, C. Documentação pedagógica e avaliação na educação infantil: um caminho para a transformação. Porto Alegre: Penso, 2019. p. 26-56.

FORMOSINHO, Júlia Oliveira; PASCAL, Christine. Documentação pedagógica e avaliação na educação infantil. Porto Alegre: Penso, 2019.

GARZON, Adriana Marcela Monroy; SILVA, Kênia Lara da; MARQUES, Rita de Cássia. Pedagogia crítica libertadora de Paulo Freire na produção científica da Enfermagem 1990-2017. Revista Brasileira de Enfermagem, São Paulo, v. 71, n. Suppl. 4, p. 18541861, jan. 2018.

GOULART, Milayni Ludmila Santos. Viajando no Mundo da Literatura Infantil: Uma experiência pedagógica nas aulas de Educação Física. Cadernos de Formação, Rio de Janeiro, v. 9, n. 1, p. 65-75, mar. 2018.

LANKSHEAR, Colin.; KNOBEL, Michele. Pesquisa pedagógica: do projeto à implementação. Porto Alegre: Artmed, 2008. 
Educação física escolar na educação infantil: uma revisão sistemática

Uirá de Siqueira Farias • Daniel Teixeira Maldonado • Vinicius dos Santos Moreira • Elisabete dos

Santos Freire • Graciele Massoli Rodrigues

LONGO, Monique Marques; XAVIER, Isis Gabrielli Gomes. A formação de professores de educação física escolar infantil no Brasil.

Revista Portuguesa de Ciencias do Desporto, Porto - Portugal , v. 17, n. 3, p. 63-78, 2017.

MALDONADO, Daniel Teixeira; SILVA, Sheila Aparecida Pereira dos Santos; MIRANDA, Maria Luiza de Jesus. Pesquisa sobre a Educação Física no cotidiano da escola: o estado da arte. Movimento, Porto Alegre, v. 20, n. 4, p. 1373-1395, out./dez. 2014.

MARTINS, Rodrigo Lema Del Rio. O lugar da Educação Física na Educação Infantil. 2018. 212 f. Tese (Doutorado em Educação Física) - Centro de Educação Física e Desportos, Universidade Federal do Espírito Santo,Vitória, 2018.

MARTINS, Rodrigo Lema Del Rio; BARBOSA, Raquel Firmino Magalhães; MELLO, André da Silva. Educação Física e Educação Infantil: o estado do conhecimento sobre a formação docente. Arquivos Brasileiros de Educação Física, Tocantinópolis, v. 1, n. 1, p. 135-155, jan./jul. 2018.

MARTINS, Rodrigo Lema Del Rio; MELLO, André da Silva. Perfil profissional dos professores de Educação Física que atuam na Educação Infantil Públicas das Capitais Brasileiras. Humanidades e Inovação, Tocantins, v. 6, n. 15, p. 160-172, 2019.

MELLO, André da Silva. et al. Educação Física na Educação Infantil: em estudo em periódicos da área. In: MELLO, André da Silva; SANTOS, W. D. Educação Física na Educação Infantil: práticas pedagógicas no cotidiano escolar. Curitiba: CRV, 2012. p. 41-56.

MELLO, André da Silva et al. Representações Sociais sobre a Educação Física na Educação Infantil. Revista de Educação Física/UEM, Maringá, v. 23, n. 3, p. 443-455, 2012b.

MELLO, André da Silva et al. Educação Física na Educação Infantil: Produção de Saberes no Cotidiano Escolar. Revista Brasileira de Ciências do Esporte, Florianópolis, v. 36, n. 2, p. 467-484, abr./ jun. 2014. 
Educação física escolar na educação infantil: uma revisão sistemática

Uirá de Siqueira Farias • Daniel Teixeira Maldonado • Vinicius dos Santos Moreira • Elisabete dos Santos Freire · Graciele Massoli Rodrigues

MELLO, André da Silva et al. Educação Infantil na Base Nacional Comum Curricular: pressupostos e interfaces com a Educação Física. Motrivivência, Florianópolis, v. 28, n. 48, p. 130-149, 2016. MELLO, André da Silva et al. Educação Física na Educação Infantil: Do isolamento pedagógico à articulação com outras áreas do conhecimento. Revista Kinesis, Santa Maria, v. 36, n. 3, p. 15-27, set./dez. 2018.

MOURA, Diego Luz.; COSTA, Kamila Ribeiro Nunes; ANTUNES, Marcelo Moreira. Educação Física e Educação Infantil: Uma análise em seis periódicos nacionais. Pensar a Prática, Goiânia, v. 19, n. 1, p. 182-195, jan./mar. 2016.

NÓVOA, António. Os professores da virada do milênio: do excesso dos discursos à pobreza das práticas. Educação e Pesquisa, São Paulo, v. 25, n. 1, p. 11-20, 1999.

QVORTRUP, Jens. A infância enquanto categoria estrutural.

Educação e Pesquisa, São Paulo, v. 36, n. 2, p. 631-643, mai./ago. 2010.

\section{ROCHA, Maria Celeste. Forma escolar, Educação Física e} Educação Infantil: (im)pertinências. 2011. 133 f. Dissertação (Mestrado em Educação Física) - Centro de Educação Física e Desportos, Universidade Federal do Espírito Santo, Vitória, 2011. RODRIGUES, Renata Marques; FIGUEIREDO, Zenólia Campos. Construção identitária da professora de Educação Física em uma instituição de Educação Infantil. Movimento, Porto Alegre, v. 17, n. 4, p. 65-81, out./dez. 2011.

RODRIGUES, Renata Marques; FIGUEIREDO, Zenólia Christina.; ANDRADE FILHO, Nelson Figueiredo. Relações socioprofissionais como elementos de influência na construção das identidades docentes. Movimento, Porto Alegre, v. 18, n. 4, p. 175-195, out./ dez. 2012.

SAMPAIO, Rosana Ferreira; MANCINI, Marisa Cotta. Estudos de revisão sistemática: um guia para síntese criteriosa da evidência científica. Revista Brasileira de Fisioterapia, São Carlos, v. 11, n. 1, p. 83-89, 2007. 
Educação física escolar na educação infantil: uma revisão sistemática

Uirá de Siqueira Farias • Daniel Teixeira Maldonado • Vinicius dos Santos Moreira • Elisabete dos

Santos Freire • Graciele Massoli Rodrigues

SARMENTO, Manuel Jacinto. A sociologia da infância e a sociedade contemporânea: desafios conceituais e praxeológicos. In: ENS, Romilda Teodora.; GARANHANI, Marynelma Camargo (org.). Sociologia da Infância e a formação de professores. São Paulo: Editora Universitária Champagnat, v. I, 2013. p. 13-46.

SAYÃO, Deborah Thomé. Educação Física na Pré-Escola: da especialização disciplinar à possbilidade de trabalho pedagógico integrado. Dissertação (Mestrado em Educação) - Centro de Ciências em Educação, Universidade Federal de Santa Catarina. Florianópolis, 1996.

SAYÃO, Deborah Thomé. Cabeças e corpos, adultos e crianças: cadê o movimento e quem separou tudo isso? Revista Eletrônoca de Educação, São Carlos, v. 2, n. 2, p. 92-105, nov. 2008.

SAYÃO, Deborah Thomé. Educação Física na Educação Infantil: riscos, conflitos e controvérsias. Motrivivência, Florianópolis, Ano XI, n. 13, p. 221-238, novembro, 1999.

SOUZA, Barbara Isabela Soares. A organização do trabalho pedagógico na educação infantil: Especificidades e relações com a Educação Física. Motrivivência, Florianópolis, v. 31, n. 58, p. 01-22, abr./jul. 2019.

SOUZA, Marília Menezes Nascimento; NEIRA, Marcos Garcia. Tematizando a Cultura Corporal na Educação Infantil: uma experiência multiculturalmente orientada. Cadernos de Formação RBCE, Rio de Janeiro, v. 6. n.1, p. 58-68, 2015.

SURDI, Aguinaldo Cesar; MELO, José Pereira; KUNZ, Elenor. O brincar e o se-movimentar nas aulas de Educação Física Infantil: realidades e possibilidades. Movimento, Porto Alegre, v. 22, n. 2, p. 459-470, abr./jun. 2016.

VAZ, Alexandre Fernandez. Dos corpos infantis em ambientes educacionais. Cadernos de Formação RBCE, Rio de Janeiro, v. 9, n. 2, p. 47-56, 2018. 
Educação física escolar na educação infantil: uma revisão sistemática

Uirá de Siqueira Farias • Daniel Teixeira Maldonado • Vinicius dos Santos Moreira • Elisabete dos Santos Freire $\cdot$ Graciele Massoli Rodrigues

\section{Publisher}

Universidade Federal de Goiás. Faculdade de Educação Física e Dança. Publicação no Portal de Periódicos UFG. As ideias expressadas neste artigo são de responsabilidade de seus autores, não representando, necessariamente, a opinião dos editores ou da universidade. 